\title{
Fortification of Preservation Solution With Nitroprusside Does Not Alter Lung Allograft Survival in Clinical Human Lung Transplantation
}

\author{
Joshua A. Boys, MD, ${ }^{1}$ Michael E. Bowdish, MD, ${ }^{2,3}$ Ram Kumar Subramanyan, MD, PhD, ${ }^{2}$ \\ Kimberly A. Shemanski, MD, ${ }^{2}$ Gundeep S. Dhillon, MD, MPH, ${ }^{4}$ Koichi Toda, MD, ${ }^{5}$ Johanna Perrillo, RN, ${ }^{6}$ \\ Leonardo Seoane, MD, ${ }^{7,8}$ Michael J. Bates, MD, ${ }^{6,8}$ P. Eugene Parrino, MD, ${ }^{6}$ Hannah Kooperkamp, MD, ${ }^{6}$ \\ Vincent G. Valentine, MD, ${ }^{9}$ W. Brooks Emory, MD, ${ }^{10}$ John L. Ochsner, MD, ${ }^{6,8}$ P. Michael McFadden, MD ${ }^{2}$ \\ ${ }^{1}$ Division of Cardiothoracic Surgery, Department of Surgery, University of California, San Diego, San Diego, CA ${ }^{2}$ Division of Cardiothoracic \\ Surgery, Department of Surgery, Keck School of Medicine of the University of Southern California, Los Angeles, CA ${ }^{3}$ Department of \\ Preventive Medicine, Keck School of Medicine of the University of Southern California, Los Angeles, CA ${ }^{4}$ Heart-Lung Transplant Program, \\ Stanford University School of Medicine, Stanford, CA ${ }^{5}$ Department of Cardiovascular Surgery, Osaka University Graduate School of \\ Medicine, Osaka, Japan ${ }^{6}$ Division of Thoracic and Cardiovascular Surgery, Department of Surgery, Ochsner Clinic Foundation, New \\ Orleans, LA ${ }^{7}$ Division of Pulmonary Medicine and Lung Transplantation, Department of Medicine, Ochsner Clinic Foundation, New Orleans, \\ LA $^{8}$ The University of Queensland Faculty of Medicine, Ochsner Clinical School, New Orleans, LA ${ }^{9}$ Division of Pulmonary, Allergy, and \\ Critical Care Medicine, The Kirklin Clinic, University of Alabama School of Medicine, Birmingham, AL ${ }^{10}$ Division of Pulmonary Medicine, \\ Department of Medicine, Ochsner Clinic Foundation, New Orleans LA
}

Background: Nitric oxide improves gas exchange following primary lung allograft dysfunction. Nitroprusside, a potent nitric oxide donor, has reduced reperfusion injury and improved oxygenation in experimental lung transplantation.

Methods: We sought to study the effect on lung allograft outcomes of fortifying the preservation solution with nitroprusside. We conducted a single-center clinical study of 46 consecutive lung recipients between 1998 and 2000: 24 patients received donor organs preserved in modified Euro-Collins solution with prostaglandin E1 (PGE1) (control group), and 22 patients received organs preserved in modified Euro-Collins with PGE1 and nitroprusside (NP group). The primary endpoint was overall survival.

Results: Baseline characteristics were similar between the groups except for a significantly longer graft ischemic time in the NP group vs the control group ( $253.3 \pm 52$ vs $225.3 \pm 41$ minutes, respectively, $P=0.04$ ). No significant differences were found in partial pressure arterial oxygen to fraction inspired oxygen ratio at $\leq 48$ hours, primary graft dysfunction, or bronchiolitis obliterans-free days. Overall survival at 1, 3, and 5 years was $89 \%, 73 \%$, and $63 \%$ in the control group and $76 \%, 38 \%$, and $23 \%$ in the NP group. Log-rank survival analysis showed that the NP group had a significantly increased risk of mortality $(P=0.034)$ compared to the control group.

Conclusion: The addition of nitroprusside to the lung transplant perfusate in this clinical trial did not improve survival; however, a large randomized trial would likely reduce confounding ischemia times and increase the power of the study.

Keywords: Graft survival, lung transplantation, nitroprusside, primary graft dysfunction

Address correspondence to P. Michael McFadden, MD, Division of Cardiothoracic Surgery, Department of Surgery, Keck School of Medicine of the University of Southern California, 1520 San Pablo Street, Suite 4300, Los Angeles, CA 90033. Tel: (323) 442-5849. Email: michael.mcfadden@med.usc.edu

\section{INTRODUCTION}

Lung transplantation is a viable therapeutic option in the setting of pulmonary parenchymal or vascular disorders that are refractory to medical therapy. As the outcomes of lung transplantation and immunosuppression have improved, the number of lung transplants and the demand for organ allocation have increased without any growth in the donor pool. Only approximately $10 \%$ to $20 \%$ of donor lungs are appropriate for transplantation. ${ }^{1}$ Because of the limited availability of donors, marginal donor lungs are increasingly being used. The primary challenge of the transplant team is to optimize all efforts to prevent injury to the allograft.

Despite refinements in perioperative management and surgical techniques, primary graft dysfunction (PGD) remains a significant complication within the first 72 hours of lung transplantation. PGD is a subjective measure and is estimated to affect $30 \%$ of lung transplant recipients. ${ }^{2-5}$ Donor-acquired and recipient-related risk factors have been 
extensively studied in an attempt to understand and to have an impact on PGD, as any level of PGD has been shown to influence long-term outcomes of increased bronchiolitis obliterans and mortality. ${ }^{6,7}$ Significant attention has been directed toward improving lung preservation techniques as well. To this end, several refinements have been made to the type of lung preservation solution; the volume, pressure, and temperature of the flush solution; the use of retrograde flush methodology; allograft storage and transport; and the use of prostaglandin and nitric oxide therapy. Both animal and human studies have shown that endogenous nitric oxide is reduced in allografts with clinical PGD. ${ }^{8-10}$ Nitric oxide prevents neutrophil adhesion to endothelial cells and reduces vascular tone; therefore, it is thought to be a key player in PGD. ${ }^{11}$ Thus, efforts have been directed to compensate for the depressed endogenous nitric oxide levels in PGD. Several studies have looked at the effect of inhaled nitric oxide in preventing PGD. Although inhaled nitric oxide has been shown to improve gas exchange following PGD, it has not shown definitive evidence of reducing PGD. ${ }^{12,13}$ Nitroprusside, a potent donor of nitric oxide, reduced PGD in experimental animal models for lung transplantation. ${ }^{14}$ Furthermore, King et al reported that immediate graft dysfunction secondary to ischemia-reperfusion injury was associated with donor allograft pulmonary hypertension. ${ }^{15}$ This finding provides a physiologic mechanism for how nitroprusside, a vasodilator, could influence PGD. We sought to determine the effect of nitroprusside on overall survival after clinical lung transplantation.

\section{METHODS Patients}

All adult patients with nonmalignant, end-stage lung disease who underwent a deceased donor single lung transplantation or bilateral sequential lung transplantation at the Ochsner Clinic between January 1998 and June 2000 were included in this cohort. This study was undertaken in accordance with good clinical practices and was approved by the Ochsner Institutional Review Board. Informed consent was obtained from recipients prior to transplantation.

\section{Donor and Recipient Lung Transplantation Surgery}

Donor selection was based on the widely accepted guidelines of adequate gas exchange and bronchoscopic evaluation to exclude purulent secretions. ${ }^{16}$ At the time of lung recovery, standard organ procurement techniques were utilized for lung transplantation. Cold Euro-Collins (Baxter Healthcare Corporation) preservation solution was infused via the pulmonary artery in an antegrade fashion, with the lungs inflated to two-thirds of their tidal volume. For the initial 24 recipient patients (control group), 4 liters of modified Euro-Collins solution followed by $500 \mu \mathrm{g}$ of prostaglandin $\mathrm{E} 1$ (PGE1) at $4^{\circ} \mathrm{C}$ in situ was flushed into the donor pulmonary arterial circulation to effect pulmonary vasodilation and promote uniform distribution of the lung preservation solution, and then the donor lungs were cooled topically with sterile iced saline slush. The lungs for the next 22 recipient patients (NP group) underwent the same protocol except for the addition of $10 \mathrm{mg}$ of nitroprusside following the modified Euro-Collins and PGE1 infusion. Retrograde flushing of the lungs was then performed either in situ or at the back table with $1 \mathrm{~L}$ of cold Euro-Collins solution in each of the 4 pulmonary veins. Following administration of the preservative, the tracheobronchial tree was stapled and secured in iced preservative and transported to our recipient transplant center. Single lung transplantation was performed through a posterolateral thoracotomy. Bilateral lung transplantation was performed through bilateral anterolateral transsternal thoracotomy (clamshell incision). Cardiopulmonary bypass requirement was based on the pulmonary artery hemodynamic profile, intolerance of contralateral single lung ventilation, and hemodynamic instability.

Immunosuppression was achieved preoperatively with intravenous methylprednisolone and azathioprine without the use of induction therapy. Postoperative immunosuppression consisted of corticosteroids, azathioprine, and tacrolimus. Transesophageal echocardiography was performed only in select cases to detect pulmonary artery or vein obstruction. Microbiological alveolar sampling was performed prior to extubation. Clinical data were obtained by chart review during follow-up.

\section{Definition of Graft Ischemia Time}

Graft ischemia time was defined as the time interval between the application of the aortic cross-clamp during procurement and the reperfusion of the allograft in the recipient. In the bilateral lung transplantation cases, the longest allograft ischemic time was recorded.

\section{Definition of Primary Graft Dysfunction}

This study identified patients with PGD based on how the International Society for Heart and Lung Transplantation currently defines grade 2 and grade 3 PGD. PGD is categorized into grade 0 to 3 , based on pulmonary edema on chest $x$-ray and the partial pressure arterial oxygen to fraction inspired oxygen $\left(\mathrm{PaO}_{2} / \mathrm{FiO}_{2}\right)$ ratio. ${ }^{17}$ Grade $2 \mathrm{PGD}$ is defined by the presence of radiographic infiltrate development in the allograft within the first 48 hours following lung transplantation and $\mathrm{PaO} / \mathrm{FiO}_{2}$ ratio between $200-300$ also within the first 48 hours. Grade 3 PGD is defined by the presence of radiographic infiltrate development in the allograft within the first 48 hours following lung transplantation and a $\mathrm{PaO}_{2} / \mathrm{FiO}_{2}$ ratio $<200$ within the first 48 hours. The absence of clinical evidence of bacterial infection, atelectasis, or rejection was also an aspect of the PGD criteria used for this study.

\section{Study Endpoints}

The primary endpoint was overall survival. Secondary endpoints included mean 24-hour transfusion requirement; best $\mathrm{PaO}_{2} / \mathrm{FiO}_{2}$ ratio within the first postoperative hour, within hours 12-24, and within hours 24-48; time to extubation; length of stay; PGD within 24 hours and after 24 hours; forced expiratory volume within 1 second $\left(\mathrm{FEV}_{1}\right)$ at 12 months; and number of days free from bronchiolitis obliterans.

\section{Statistical Analysis}

Normally distributed continuous data are reported as mean values and standard deviations while non-normal continuous data are reported as medians and interquartile ranges (IQR). Comparison between groups was by Student $t$ test if continuous variables were normally distributed; otherwise, the Wilcoxon rank sum test was used. 


\begin{tabular}{lccc}
\hline \multicolumn{1}{c}{ Variable } & $\begin{array}{c}\text { Control Group } \\
\mathbf{n = 2 4}\end{array}$ & $\begin{array}{c}\text { Nitroprusside Group } \\
\mathbf{n = 2 2}\end{array}$ & $\boldsymbol{P}$ Value \\
\hline Sex, male, $\mathrm{n}(\%)$ & $13(54.2)$ & $11(50)$ & 1.0 \\
Mean age, years \pm SD & $42.8 \pm 12.3$ & $40.6 \pm 18.6$ & 0.64 \\
Bilateral lung transplant, $\mathrm{n}(\%)$ & $19(79.2)$ & $13(59)$ & 0.2 \\
Single lung transplant, $\mathrm{n}(\%)$ & $5(20.8)$ & $9(40.9)$ & 0.2 \\
Cardiopulmonary bypass, $\mathrm{n}(\%)$ & $4(16.7)$ & $5(22.7)$ & 0.61 \\
Mean operative time, minutes \pm SD & $345.3 \pm 95$ & $374.3 \pm 141.8$ & 0.43 \\
Mean ischemia time, minutes \pm SD & $225.3 \pm 41$ & $253.3 \pm 52$ & 0.04 \\
Inhaled nitric oxide used postoperatively, $\mathrm{n}(\%)$ & $1(4.2)$ & $5(22.7)$ & 0.07 \\
\hline
\end{tabular}

Categorical data are expressed as counts and percentages and were compared by either chi-square or Fisher exact test.

Survival analysis was performed by Kaplan-Meier methods. The log-rank test was used to determine equality between treatment cohorts. To examine the effect of nitroprusside use on long-term survival, univariable and multivariable Cox proportional hazard modeling was performed. Given the small sample size, the multivariable model was used to include preoperative and operative variables with a $P<0.02$ on univariable Cox modeling in the multivariable model of preoperative factors, operative factors, and death. Statistical significance was defined as $P<0.05$.

\section{RESULTS \\ Recipients}

Forty-six patients were enrolled in this study, with 22 in the NP group. Baseline characteristics were similar across groups except for significantly longer graft ischemic time in the NP group vs the control group $(253.3 \pm 52$ vs $225.3 \pm$ 41 minutes, respectively, $P=0.04$ ) (Table 1 ). We found no difference between the patients in the 2 groups who had a single or a bilateral transplant. Cystic fibrosis and emphysema were the 2 most common causes for transplantation, but no differences were seen between groups based on recipient diagnosis (Table 2).

Table 2. Indication for Transplantation by Treatment Group

\begin{tabular}{lcc}
\hline & \multicolumn{2}{c}{ Control Nitroprusside } \\
& Group & Group \\
\multicolumn{1}{c}{ Recipient Pathology } & $\mathbf{n = 2 4}$ & $\mathbf{n = 2 2}$ \\
\hline Cystic fibrosis & $7(29.2)$ & $8(36.4)$ \\
Chronic obstructive pulmonary disease & $2(8.3)$ & 0 \\
Eisenmenger syndrome & 0 & $1(4.5)$ \\
Emphysema & $8(33.3)$ & $5(22.7)$ \\
Idiopathic pulmonary fibrosis & $4(16.7)$ & $6(27.3)$ \\
Bronchiolitis obliterans & $1(4.2)$ & $2(9.1)$ \\
Sarcoidosis & $2(8.3)$ & 0 \\
\hline
\end{tabular}

Notes: Data are presented as $\mathrm{n}(\%) . P>0.05$ for each comparison.

\section{Donors}

The donor causes of death were head trauma (54.3\%), stroke (39.1\%), central nervous system tumor (2.2\%), anoxia (2.2\%), and unknown (2.2\%). The median donor age was 40 years [IQR 29-56 years]. We found no differences in donor characteristics between the control and NP groups.

\section{Overall Survival}

Survival at 1,3 , and 5 years was $89 \%, 73 \%$, and $63 \%$ in the control group and $76 \%, 38 \%$, and $23 \%$ in the NP group. Log-rank survival analysis showed that the NP group had a significantly increased risk of mortality $(P=0.034)$ compared to the control group (Figure). Univariable predictors of death included a preoperative diagnosis of bronchiolitis obliterans, the use of inhaled nitric oxide, and the use of nitroprusside (Table 3). None of the donor characteristics was associated with increased mortality.

Using a $P$ value $<0.02$ on univariable Cox modeling, multivariable analysis of the risk of death identified ischemic time and nitroprusside use as risk factors. After adjusting for ischemic time, nitroprusside use was no longer a statistically significant risk factor for death (hazard ratio $[\mathrm{HR}] 1.83 \pm 0.62$, 95\% confidence interval $[\mathrm{Cl}]$ 0.93-3.5, $P=0.075)$.

\section{Secondary Outcomes}

The NP group showed a trend for lower $\mathrm{PaO}_{2} / \mathrm{FiO}_{2}$ ratios at 1 hour, 12-24 hours, and 24-48 hours; however, the differences between the NP and control groups were not significant (Table 4). In addition, we found no differences in the evidence of PGD at 24 hours and after 24 hours between the 2 groups. Further, we found no significant difference between groups in bronchiolitis obliterans-free days.

\section{DISCUSSION}

To our knowledge, this is the first clinical study in which nitroprusside was used following PGE1 in donor lungs flushed with modified Euro-Collins solution in patients undergoing lung transplantation. We compared these patients to 24 patients who received lungs that had the standard flush and found no difference in survival after adjusting for ischemic time or in PGD; these findings are different from those of previous studies using nitroprusside.

Yamashita et al investigated single-lung allotransplantation performed on 10 dogs, with one group receiving 


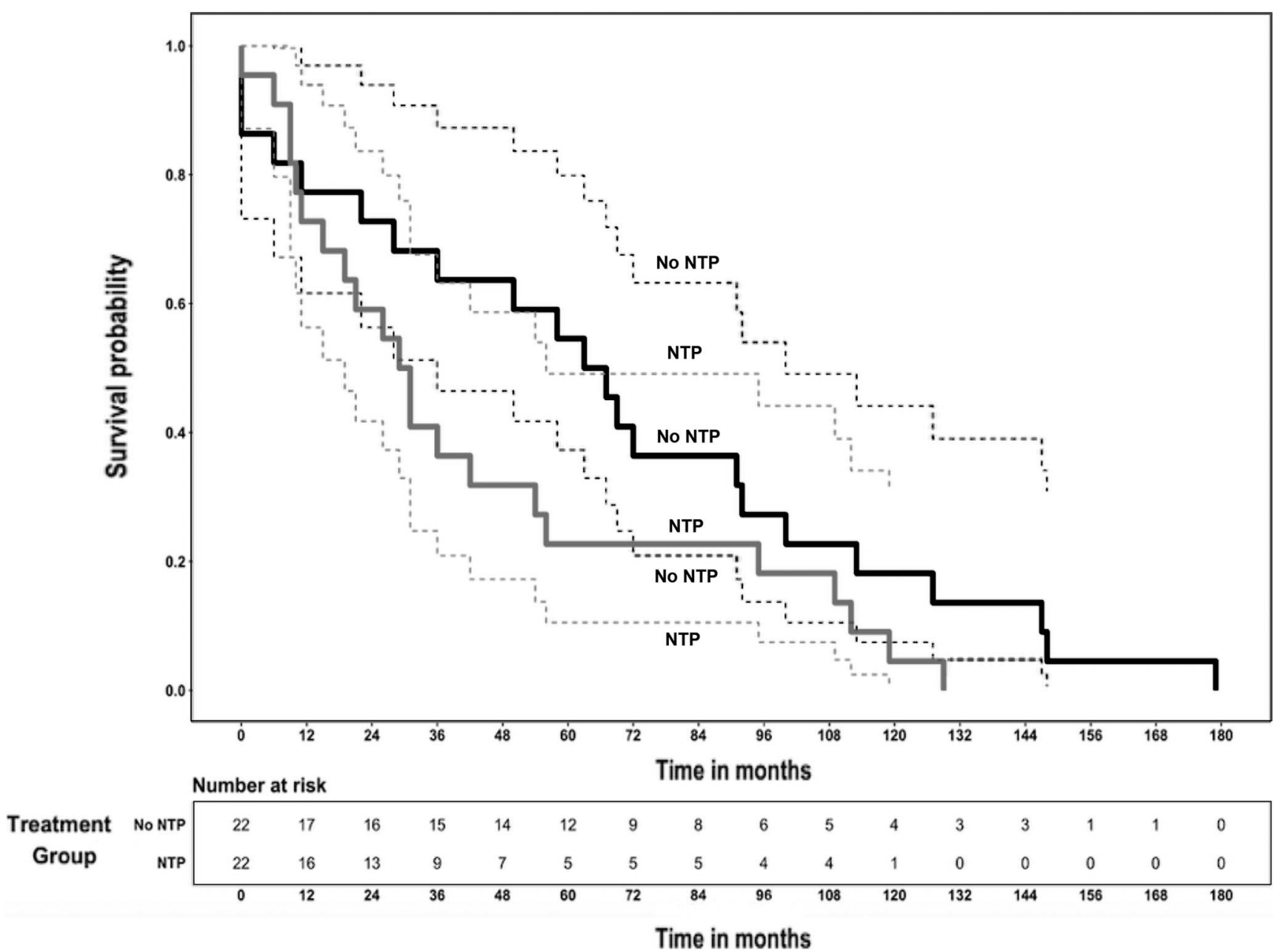

Figure. Survival curves of Kaplan-Meier estimate. Log-rank survival in months: no nitroprusside (No NTP) vs nitroprusside (NTP); $P=0.034$.

nitroprusside in the perfusate vs a control group. ${ }^{14}$ At 6 hours postreperfusion, they found increased $\mathrm{PaO}_{2}$ oxygenation with nitroprusside, but we found no difference in our $\mathrm{PaO}_{2} / \mathrm{FiO}_{2}$ ratio up to 48 hours from transplantation in our study. Another independent group performed a similar study in rabbits with nitroprusside in the perfusate compared to a control group, and they also found improvements in posttransplant oxygenation at 30 minutes postreperfusion, similar to the Yamashita study. ${ }^{15}$ The reason for these differences is likely the short follow-up time in the Yamashita and King studies, ${ }^{14,15}$ which would reflect early physiologic changes posttransplantation and may potentially be lost within the first 48 hours, as suggested by our findings.

The small sample size of our study makes it prone to a type 1 error in that it may be underpowered to detect small but clinically relevant physiologic differences. Additionally, the prolonged ischemia time in the NP group may have confounded the results.

A technical difference in this study from current practice is the use of Euro-Collins solution compared to the current use of Perfadex (Vitrolife) for lung preservation. While the use of
Euro-Collins makes it difficult to draw modern parallels, fortifying Perfadex with nitroprusside may yield different results from our current study.

In our control patients, the 1-, 3-, and 5-year survival rates were $89 \%, 73 \%$, and $63 \%$. The Organ Procurement and Transplantation Network records 1-, 3-, and 5-year survival rates of $86 \%, 63 \%$, and $53 \%$ for similarly aged recipients from $2008-2015 .{ }^{18}$ While our study data are 20 years old, the similarity between our study's control survivorship and current survivorship demonstrates that our study is relevant, as the 1-, 3-, and 5-year survival rates for lung transplantation have not significantly improved. Further investigations into improving lung transplant survival are important and should be reported.

\section{CONCLUSION}

The addition of nitroprusside in the lung transplant perfusate in this clinical trial showed no difference in survival after adjusting for ischemic time; however, given the nonrandomized nature of this study, a randomized control trial may better help clarify the potential role of nitroprusside in lung transplantation. 
Table 3. Univariable Cox Proportional Hazard Modeling of Risk Factors for Death

\begin{tabular}{|c|c|c|c|}
\hline Variable & Hazard Ratio & $\mathbf{9 5 \%}$ Confidence Interval & $P$ Value \\
\hline Recipient age, years & 0.99 & $0.97-1.0$ & 0.65 \\
\hline Ischemic time, per 10 minutes & 1.06 & 0.99-1.1 & 0.05 \\
\hline Transfusion, each & 0.98 & $0.92-1.0$ & 0.53 \\
\hline Ventilator time, hours & 1.00 & $0.99-1.0$ & 0.40 \\
\hline Intensive care unit, days & 1.00 & $0.99-1.1$ & 0.10 \\
\hline Length of stay, days & 1.00 & $0.99-1.0$ & 0.26 \\
\hline Height, $\mathrm{cm}$ & 1.80 & $0.04-81$ & 0.74 \\
\hline Weight, kg & 0.99 & $0.97-1.0$ & 0.87 \\
\hline Body mass index, $\mathrm{kg} / \mathrm{m}^{2}$ & 0.98 & $0.09-1.1$ & 0.66 \\
\hline Recipient sex, male & 1.40 & $0.74-2.7$ & 0.29 \\
\hline Donor cytomegalovirus positive & 1.09 & $0.55-2.1$ & 0.79 \\
\hline Recipient cytomegalovirus positive & 1.11 & $0.58-2.1$ & 0.73 \\
\hline Caucasian & 0.61 & $0.21-1.8$ & 0.38 \\
\hline Bilateral lung transplant & 0.75 & $0.37-1.4$ & 0.42 \\
\hline Cardiopulmonary bypass & 2.09 & $0.89-4.8$ & 0.08 \\
\hline Inhaled nitric oxide & 5.50 & $1.9-15$ & 0.001 \\
\hline Chronic obstructive pulmonary disease & 1.90 & $0.42-9.1$ & 0.39 \\
\hline Eisenmenger syndrome & 0.81 & $0.10-6.4$ & 0.84 \\
\hline Emphysema & 1.45 & $0.62-3.4$ & 0.38 \\
\hline Idiopathic pulmonary fibrosis & 1.10 & $0.42-2.8$ & 0.85 \\
\hline Bronchiolitis obliterans & 6.90 & $1.7-28.0$ & 0.006 \\
\hline Sarcoidosis & 1.63 & $0.2-13.0$ & 0.64 \\
\hline Nitroprusside & 2.00 & $1.0-3.8$ & 0.039 \\
\hline Donor age, years & 0.99 & $0.97-1.0$ & 0.64 \\
\hline Donor sex, male & 1.41 & $0.74-2.6$ & 0.29 \\
\hline
\end{tabular}

Table 4. Outcomes by Treatment Group

\begin{tabular}{|c|c|c|c|}
\hline Variable & $\begin{array}{l}\text { Control } \\
\text { Group } \\
n=24\end{array}$ & $\begin{array}{l}\text { Nitroprusside } \\
\text { Group } \\
n=22\end{array}$ & $P$ Value \\
\hline Transfusion within 24 hours, mean \pm SD & $4.48 \pm 0.9$ & $4.45 \pm 6.5$ & 0.9 \\
\hline $\mathrm{PaO}_{2} / \mathrm{FiO}_{2}$ ratio at $<1$ hour, mean $\pm \mathrm{SD}$ & $283.7 \pm 183.4$ & $228.6 \pm 162.3$ & 0.29 \\
\hline $\mathrm{PaO}_{2} / \mathrm{FiO}_{2}$ ratio at $12-24$ hours, mean $\pm \mathrm{SD}$ & $241.8 \pm 128.4$ & $228.8 \pm 115.3$ & 0.72 \\
\hline $\mathrm{PaO}_{2} / \mathrm{FiO}_{2}$ ratio at $\geq 24-48$ hours, mean $\pm S D$ & $288.1 \pm 127$ & $260.4 \pm 112.3$ & 0.44 \\
\hline Mean ventilator time, hours $\pm S D$ & $81 \pm 142.1$ & $55 \pm 83.5$ & 0.45 \\
\hline Mean length of stay, days \pm SD & $37 \pm 83.4$ & $20.3 \pm 15.5$ & 0.30 \\
\hline Primary graft dysfunction at $<24$ hours, n (\%) & $9(37.5 \%)$ & $11(50 \%)$ & 0.55 \\
\hline Primary graft dysfunction at $\geq 24$ hours, n (\%) & $9(37.5 \%)$ & $7(31.8 \%)$ & 0.76 \\
\hline $\mathrm{FEV}_{1}$ percentage at 12 months, mean $\pm \mathrm{SD}$ & $75.7 \pm 18.8$ & $71.5 \pm 18.5$ & 0.57 \\
\hline Bronchiolitis obliterans-free days, mean \pm SD & $1,220 \pm 948.8$ & $879 \pm 741.1$ & 0.18 \\
\hline
\end{tabular}

$\mathrm{FEV}_{1}$, forced expiratory volume in 1 second; $\mathrm{PaO}_{2} / \mathrm{FiO}_{2}$, partial pressure arterial oxygen to fraction inspired oxygen ratio. 


\section{ACKNOWLEDGMENTS}

The early results of this study were submitted and accepted as an abstract for a poster presentation at the 13th World Congress of the World Society of Cardiothoracic Surgeons in 2003. The authors have no financial or proprietary interest in the subject matter of this article.

\section{REFERENCES}

1. Mulligan MS, Shearon TH, Weill D, Pagani FD, Moore J, Murray S. Heart and lung transplanation in the United States, 1997-2006. Am J Transplant. 2008 Apr;8(4 Pt 2):977-987. doi: 10.1111/j.1600-6143.2008.02175.x.

2. Diamond JM, Arcasoy S, Kennedy CC, et al. Report of the International Society for Heart and Lung Transplantation Working Group on primary lung graft dysfunction, part II: epidemiology, risk factors, and outcomes-a 2016 consensus group statement of the International Society for Heart and Lung Transplantation. J Heart Lung Transplant. 2017 Oct;36(10):1104-1113. doi: 10.1016/j.healun.2017.07.020.

3. Christie JD, Sager JS, Kimmel SE, et al. Impact of primary graft failure on outcomes following lung transplantation. Chest. 2005 Jan;127(1):161-165. doi: 10.1378/chest.127.1.161.

4. Christie JD, Bavaria JE, Palevsky $\mathrm{HI}$, et al. Primary graft failure following lung transplantation. Chest. 1998 Jul;114(1):51-60. doi: 10.1378/chest.114.1.51.

5. Gray WH, McFadden PM. Commentary: evaluation of primary graft dysfunction after lung transplantation-it is time to teach an old dog new tricks! J Thorac Cardiovasc Surg. 2019 Apr 24. pii: S0022-5223(19)30906-7. doi: 10.1016/j.jtcvs.2019.04.012.

6. Whitson BA, Nath DS, Johnson AC, et al. Risk factors for primary graft dysfunction after lung transplantation. $J$ Thorac Cardiovasc Surg. 2006 Jan;131(1):73-80. doi: 10.1016/j.jtcvs.2005.08.039.

7. Daud SA, Yusen RD, Meyers BF, et al. Impact of immediate primary lung allograft dysfunction on bronchiolitis obliterans syndrome. Am J Respir Crit Care Med. 2007 Mar 1;175(5):507-513. doi: 10.1164/rccm.200608-10790C.

8. Pinsky DJ, Naka Y, Chowdhury NC, et al. The nitric oxide/cyclic GMP pathway in organ transplantation: critical role in successful lung preservation. Proc Natl Acad Sci U S A. 1994 Dec 6;91(25):12086-12090.
9. Marczin N, Riedel B, Gal J, Polak J, Yacoub M. Exhaled nitric oxide during lung transplantation. Lancet. $1997 \mathrm{Dec}$ 6;350(9092):1681-1682. doi: 10.1016/S0140-6736(05)64281-X.

10. Le Cras TD, McMurtry IF. Nitric oxide production in the hypoxic lung. Am J Physiol Lung Cell Mol Physiol. 2001 Apr;280(4):L575-L582. doi: 10.1152/ajplung.2001.280.4.L575.

11. Meyer KC, Love RB, Zimmerman JJ. The therapeutic potential of nitric oxide in lung transplantation. Chest. 1998 May;113(5):1360-1371. doi: 10.1378/chest.113.5.1360.

12. Botha $P$, Jeyakanthan $M$, Rao JN, et al. Inhaled nitric oxide for modulation of ischemia-reperfusion injury in lung transplantation. J Heart Lung Transplant. 2007 Nov;26(11):1199-1205. doi: 10.1016/j.healun.2007.08.008.

13. Pasero D, Martin EL, Davi A, Mascia L, Rinaldi M, Ranieri VM. The effects of inhaled nitric oxide after lung transplantation. Minerva Anestesiol. 2010 May;76(5):353-361.

14. Yamashita M, Schmid RA, Ando K, Cooper JD, Patterson GA. Nitroprusside ameliorates lung allograft reperfusion injury. Ann Thorac Surg. 1996 Sep;62(3):791-796; discussion 796-797. doi: 10.1016/S0003-4975(96)00439-0.

15. King RC, Binns OA, Kanithanon RC, et al. Low-dose sodium nitroprusside reduces pulmonary reperfusion injury. Ann Thorac Surg. 1997 May;67(5):1398-1404. doi: 10.1016/s0003-4975(97)00250-6.

16. Bracken CA, Gurkowski MA, Naples JJ. Lung transplantation: historical perspective, current concepts, and anesthetic considerations. J Cardiothorac Vasc Anesth. 1997 Apr;11(2):220-241.

17. Snell GI, Yusen RD, Weill D, et al. Report of the ISHLT Working Group on primary lung graft dysfunction, part I: definition and grading - a 2016 consensus group statement of the International Society for Heart and Lung Transplantation. J Heart Lung Transplant. 2017 Oct;36(10):1097-1103. doi: 10.1016/j.healun.2017.07.021.

18. Region 3 data for recipient survivorship after lung transplantation based on age. Organ Procurement and Transplantation Network. U.S Department of Health \& Human Services. https://optn.transplant.hrsa.gov/data/view-datareports/regional-data/. Accessed August 13, 2019.

This article meets the Accreditation Council for Graduate Medical Education and the American Board of Medical Specialties Maintenance of Certification competencies for Patient Care, Medical Knowledge, and Practice-Based Learning and Improvement. 